\title{
Race composition of the loose smut (Ustilago tritici) in Western Siberia
}

\author{
E.A. Orlova, N.P. Bechtold \\ Siberian Research Institute for Plant Industry and Breeding - Branch of the Institute of Cytology and Genetics, SB RAS, Krasnoobsk, \\ Novosibirsk region, Russia
}

DOI 10.18699/ICG-PlantGen2019-23

() Autors, 2019

*e-mail: Orlova.Lena10@yandex.ru

\begin{abstract}
The development of rational genetic protection for new varieties depends on data on the race composition of the wheat smut pathogen caused by Ustilago tritici, as well as on intrapopulation variability of fungus. The virulence of the isolates was estimated using a differential host series of varieties. Isolates of $U$. tritici were collected on the fields of the Novosibirsk and Omsk regions, as well as the Altai Krai in 2015-2018. Two sets of a differential host series were used for inoculation. The first one was developed in Russia by V. I. Krivchenko (1987) for identification of loose smut. This set consists of 9 wheat varieties: durum wheat (three entries) and bread wheat (six entries). The another set is Canadian and it's used in foreign studies. It was made by J.J. Nielsen, P. Thomas. (1996) for identification of loose smut and consists of 19 wheat varieties, three of them are durum wheat (TD-1, TD-11, TD-19). A total of 15 isolates collected from different varieties of spring bread wheat were assessed for virulence. As an isolate, one smut spike per plant was taken. The isolate was considered as virulent to the differential host line if more than $10 \%$ of the plants were infected. The races were identified by the key proposed by V.I. Krivchenko and J.J. Nielsen and P. Thomas. In the Novosibirsk region, the race 66 identified on the Russian set dominated. In the Canadian set, it is registered as T-8. The same race was noted in the Altai Krai. Also in these regions, the race 23 was identified. On the Canadian set, it is registered as $\mathrm{T}-18$. The race 12 was identified in the Novosibirsk and Omsk regions. In addition, the race 78 was identified in the Novosibirsk region, the race 58 was identified in the Altai Krai, and the race 1 was identified in the Omsk region. All races were specific for T. aestivum varieties and were not able to infect durum wheat varieties.
\end{abstract}

Key words: spring bred wheat; loose smut; pathogen races and population.

\section{Introduction}

The development of resistant wheat varieties for production crops is one of the effective measures to wheat smut pathogen caused by Ustilago tritici (Pers.) Jens. This depends on data on the race composition of the wheat smut pathogen, as well as on intrapopulation variability of fungus. The physiological race of smut pathogens is a sample or collection of chlamydospores, which has relatively the same virulence in certain set of differential host varieties. Such a concept of "race" was introduced in accordance with the biological features of the order Ustilaginales and selection requirements, at the $6^{\text {th }}$ International Botanical Congress in Amsterdam in 1935 (quote from Krivchenko, 1984). Loose smut pathogen races were first postulated by Grevel (1930). He identified 4 races. Later, Hanna and Popp (1932), using a self-selected differential host lines set, isolated races in the $U$. tritici population that differ in virulence on the test varieties. In Russia, V.I. Krivchenko (1987) carried out extensive work on the study and identification of physiological races of the loose smut. He compiled a differential host series of varieties, which was used in many research institutions of the USSR. This set contains 78 races of the loose smut (Druzhin, Krupnov, 2008). The Canadian set, created by J.J. Nielsen, P. Thomas, includes 19 wheat varieties. This set contains 44 races of the loose smut (Nielsen, Thomas, 1996).

For smut pathogens, the selective effect of genotypes is an important factor influencing the race variability. Based on this, we can assume the specific structure of the pathogen population in each zone sowing wheat. In this regard, we made an attempt to study and compare the race composition of the Novosibirsk, Omsk and Altai populations of the pathogen. This information may be of interest to both breeders and phytopathologists.

\section{Materials and methods}

The virulence of the isolates was estimated by infection types on differential set. Isolates were collected on the fields of the Novosibirsk and Omsk regions, as well as the Altai Krai in 2015-2018. As an isolate, one smut spike per plant was taken. A total of 15 isolates collected from different varieties of spring bread wheat were assessed for virulence.

Inoculation of plants was carried out during the most susceptible phase - the beginning of flowering, when single stamens appear on the ear, emerging from 1-2 spikelets. An aqueous suspension of smut spores was used to inoculate wheat ears. The suspension is prepared at the rate of 1 gram of spores per 1 liter of water. It is prepared immediately before infection of the plants. Inoculation of ears is carried out by the syringe method. In this case, approximately $0.05 \mathrm{ml}$ of suspension is placed into each flower. A separate syringe is used for each isolate. Infected ears were marked with paper labels. Inoculated seeds were sown the following year.

Two sets of differential host series of lines were used for inoculation. One of them was from Russia (Table 1). It was 
Table 1

The Russian differential host series of varieties for determining the physiological races of loose smut of spring wheat

\begin{tabular}{lll}
\hline Differential designation & Cultivar & Variety type \\
\hline D-1 & Moscovka & Graecum \\
D-2 & Kota & Erythrospermum \\
D-3 & Preston & Erythrospermum \\
D-4 & Rümkers Dickkopf & Lutescens \\
D-5 & Reward & Velutinum \\
D-6 & Diamant & Milturum \\
D-7 & Akmolinka 5 & Hordeiforme \\
D-8 & Mindum & Hordeiforme \\
D-9 & Narodnay & Hordeiforme \\
\hline
\end{tabular}

Table 2

The Canadian set of differential host lines for determining the physiological races of loose smut of spring wheat

\begin{tabular}{ll}
\hline Differential designation & Variety or breeding line \\
\hline TD -1 & Mindum \\
TD -2 & Renfrew \\
TD -3 & Florence/Aurore \\
TD -4 & Kota \\
TD-5 & Little Club \\
TD-6 & PJ 69282 \\
TD-7 & Reward \\
TD-8 & Carma \\
TD-9 & Kearney \\
TD-10 & Red Bobs \\
TD-11 & Pentad \\
TD-12 & Thatcher/Regent \\
TD-13 & PI 29854/ Cl 7795 \\
TD-14 & Sonop \\
TD-15 & H44/ Marquis \\
TD-16 & Marroqui 588 \\
TD-17 & Marquillo/Waratah \\
TD-18 & Manitau 2/Giza 144 \\
TD-19 & Wakooma \\
\hline
\end{tabular}

Table 3

Races of Ustilago tritici identified on the Russian set of differentiating varieties

\begin{tabular}{llllllllll}
\hline \multirow{2}{*}{ Race } & \multicolumn{2}{l}{ The reaction of varieties-differentiators } & & & \\
\cline { 2 - 9 } & D-1 & D-2 & D-3 & D-4 & D-5 & D-6 & D-7 & D-8 & D-9 \\
\hline 1 & 0 & 1 & 0 & 0 & 1 & 2 & 0 & 0 & 0 \\
12 & 0 & 1 & 0 & $1-2$ & 2 & $1-2$ & 0 & 0 & 0 \\
23 & 1 & 2 & 1 & 1 & 2 & 2 & 0 & 0 & 0 \\
58 & 2 & 2 & 1 & 1 & 2 & 1 & 0 & 0 & 0 \\
66 & 0 & 2 & 0 & 2 & 2 & 2 & 0 & 0 & 0 \\
78 & 0 & 2 & 0 & 0 & 2 & 2 & 0 & 0 & 0 \\
\hline
\end{tabular}


developed by V.I. Krivchenko (1987) for identification of loose smut. It consists of 9 wheat varieties, three of them are durum wheat (Mindum, Akmolinka 5 and Narodnaya). Differentiation of resistance reactions was carried out on a scale of: 0 - no affection; 1 - affected up to $10 \%, 2$ - affected over $10 \%$. The results were compared with a key to determine physiological races.

Since 2016, isolates of $U$. tritici have been inoculated with an additional differential host lines set - Canadian, created by Nielson, Thomas (1996) (Table 2). It uses for foreign studies and consists of 19 wheat varieties, three of them are durum wheat (TD-1, TD-11, TD-19). An isolate was considered virulent to the differential host line if more than $10 \%$ of the line plants were affected.

\section{Results and discussion}

In the Russian set of test varieties from 15 isolates studied, 6 varieties $(40 \%)$ were identified as race 66,3 varieties $(20 \%)$ - as race 23,2 varieties each $(13.3 \%)$ - as races 12 and 58, 1 variety each - as races 1 and 78 (Table 3 ). The race 66 was distinguished both among isolates collected in the Novosibirsk region and in the Altai Krai. It affected the varieties Kota, Rümkers Dikkopf, Reward, Diamant. On the Canadian set, the race was detected as T- 8 and it virulent on the TD-4, TD-5, TD-7, TD-8, TD-9, TD-13, TD-15 lines.

Races 12 and 23 were found among isolates collected in breeding plots of Novosibirsk and Omsk. On the Russian set of differentiating varieties, they did not affect the varieties Moskovka (D-1), Preston (D-3). The varieties Reward (D-5) and Diamant (D-6) were susceptible to them. On the Canadian set, the both races were detected as T-18 and they were virulent on the TD-4, TD-5, TD-7, TD-8, TD-9, TD-13 lines. In addition, the race 78 was identified on the Russian set of differentiating varieties in the Novosibirsk region. According to the compatibility reaction, this race was similar to the race 23, which made it possible to combine them under one name. Race 58 was identified in a population of $U$. tritici collected from spring bread wheat in Altai Krai. Unlike the tested isolates, it is virulent for the Moskovka variety (D-1). Race 1 was found among isolates of the Omsk region. It had low virulence and the only the variety Diamant (D-7) from Russian differential set was affected. All isolated races were specific for T. aestivum varieties and were not able to infect durum wheat varieties.

\section{References}

Druzhin A.E., Krupnov V.A. Wheat and the loose smut. Saratov, 2008. Krivchenko V.I. the Resistance of cereals to the agents of smut diseases. Moscow, 1984.

Krivchenko V.I., Myagkova D.V., Zhukova A.N., Khokhlova A.P. Guidelines for the study of resistance to smut cereal crops. Leningrad, 1987.

Menzies J.G., Knox R.E., Nielsen J., Thomas P.L. Virulence of Canadian isolates of Ustilago tritici: 1964-1998, and the use of the geometric rule in understanding host differential complexity. Canadian J Plant Pathol. 2003;25:62-72.

Nielsen J., Thomas P. Loose smut. Bunt and smut diseases of wheat: Concepts and methods of disease management. Mexico, D.F.CIMMYT, 1996.

Acknowledgements. This work was supported by ICG SB RAS budget project No. 0324-2019-0039.

Conflict of interest. The authors declare no conflict of interest. 